\section{Amassing energy}

\section{P.N. Hobson}

Biomass: An International Journal.

Editors J. Coombs and D.O. Hall. Applied Science. 4/yr. $£ 106$.

Biomass, in the form of woody plant material, is now an important fuel for much of the world and in the future there seems little doubt that it will become increasingly important as a source of various forms of energy, and of chemicals.

Biomass was started about three years ago as a forum for papers on the use of biomass directly as fuel or as feedstock for physical, chemical or biological production of gaseous or liquid fuels. Energy production is the main theme of the journal; production of chemicals for other purposes has a minor role. Vegetation, grown solely or mainly for energy production, not wastes from plant or animal production or processing, is the biomass of the title, so the journal fills a niche not covered by journals dealing with processing of wastes where pollution control may be as important as energy or chemicals production.

The editorial policy and papers published show the scope of the journal is wide. Papers can, for instance, deal with governmental policies on biomass-energy production, estimates of biomass production in different countries and from different plants, or surveys of energy use and needs in communities. On the technical side topics may range from efficiencies of simple stoves to factory processes for converting biomass to fuels and experiments on the chemical, biochemical and microbiological transformation of biomass.

The journal thus spans fields covered by established biological, chemical or biotechnological journals, and the many newer versions of the latter. The bringing

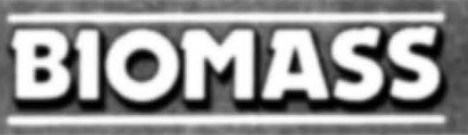

together of work concerned with the requirements for, and the optimization of production and use of, vegetable biomass specifically grown for use as fuel or feedstocks might be seen as the journal's major role; in the detailed chemical, physical and biological aspects of processing biomass it probably faces the greatest competition from the specialist journals.

Biomass is published in one volume of four, approximately 80 page, issues a year, with some five or six papers per issue. Short Communications are also published. The presentation of text, photographs and figures is good.

P.N. Hobson is Head of Microbial Biochemistry Department at the Rowett Research Institute, Aberdeen.

the new journal will achieve its own aims. It looks likely to be some years before all the Quaternary disciplines have had their treatment, if indeed they all get one. There has been little yet to win the allegiance of palaeontologists or archaeologists, to choose only two examples and geographical coverage so far is somewhat uneven: hardly a mention of Africa, for instance, home of so many dramatic discoveries of Quaternary age, while America dominates, as do American authors. But

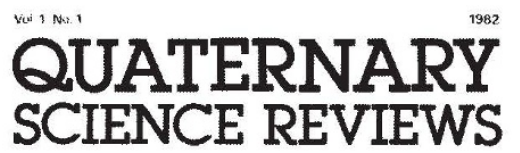

these are early days. The format and presentation seem good, if unexciting; line drawings are clear, but no photograph has yet appeared. If the journal's aspirations are really international, abstracts in languages other than English (like those in Quaternaria) should be seriously considered. The next couple of years will be crucial: with care and flexibility, Quaternary Science Reviews could win an established place.

a total of around 400 pages, an individual in a subscribing institution can pay a more reasonable rate. Authors are paid for their contributions to the journal.

The early numbers contain plenty of interest, but it is too early to assess how far
Derek Roe is a Lecturer in Prehistoric Archaeology and Director of the Donald Baden Powell Quaternary Research Centre at Oxford University.

\section{Building on artefacts}

\section{John Parkington}

Journal of Anthropological Archaeology. Editor Robert Whallon.

Academic. 4/yr. f38.35, \$48.

ArChaeOlogy is best defined as 'what archaeologists do' and this varies from the experimental manufacture and use of stone tools to the analysis of the carbon isotope composition of fossil human bones by mass-spectrometry to determine diet. With this variety it is hardly surprising to find the emergence of sub-disciplines, and, logically, the appearance of specialist journals.

We already have the Journal of Archaeological Science for the archaeometrists and the Journal of Field Archaeology essentially for field reports, and I see the Journal of Anthropological Archaeology (JAA) as a similar development designed to accommodate theoretical debate. Editor

\section{JOURNAL OF Anthropological Archaeology}

Robert Whallon says in the first issue "anthropological archaeology aims primarily to explain the organization, operation and evolution of human cultural systems" and "the JAA is intended to serve as a focus for contributions to theory and methodology in archaeology". The stress on theoretical contributions and methodological advances has grown out of what some would see as a Kuhnian revolution in the discipline in the 1960s and 1970s. In those times archaeologists began to make explicit many underlying assumptions and to recognize the search for theoretical archaeology as a valid exercise.

The articles published so far are mostly reviews which tackle significant general issues such as settlement models, ethnicity, approaches to the study of style in artefacts and the use of analogy in archaeological reasoning. Personally $I$ find the standard mixed with no one issue being of consistently memorable quality. I suspect that in choosing the theoretical and methodological slice of the archaeological cake, quality of expression and the standard of comment will be extremely critical. (Kent Flannery once remarked that at least with old archaeologists you could ignore their interpretations and use their data, but with new archaeologists there are no data). This in turn will mean that the editor will need to work hard at eliciting good copy and trimming unnecessary verbiage, something only partly achieved so far.

Having said this, it is undeniable that 